\title{
A technology of drinking water decontamination from radon and its decay products
}

Igor Voinov, Viktor P. Remez, Alexey A. Ioshin, Vladimir S. Semenishchev, Dmitry A. Gorchakov

\begin{abstract}
Underground water is one of the main sources of radon for households. This article focuses on the estimation and removal of radon from underground water using the technology and inorganic sorbents developed by EKSORB Ltd., Russia for liquid radioactive waste treatment in the nuclear power industry. The article presents the results of tests of a system for the removal of radon and radon daughters from water patented by EKSORB. This is achieved by filtering water through RATZIR sorbent, followed by periodic load regeneration. Over a period of three years, the plant is successful in removing radon from the water that had an initial radon content of approximately $1500 \mathrm{~Bq} / \mathrm{L}$ to less than $60 \mathrm{~Bq} / \mathrm{L}$, without releasing radon to indoor/outdoor air.
\end{abstract}

Keywords: Radon in drinking water • Radon measurement • Sorption

I. Voinov ${ }^{\bowtie}$

Metoils.r.o.

Milady Horakove 116/109, Prague, 16 000,

Czech Republic

E-mail: info@metoil.com

V. P. Remez, A. A. Ioshin

EKSORB Ltd.

Office 218, Build 5,

8th Marta St., Ekaterinburg, 620014, Russia

\section{S. Semenishchev}

Department of Radiochemistry and Applied Ecology

Ural Federal University

19 Mira St., Yekaterinburg, 620002, Russia

D. A. Gorchakov

EKSORB-Razvitie Ltd.

Office 334, Build 42

Bolshoy boulevard, Skolkovo Innovation Territory,

121205, Moscow, Russia

Received: 19 November 2019

Accepted: 22 January 2020

\section{Introduction}

Radon is a heavy radioactive noble gas being formed in nature due to radioactive decay of long-lived isotopes of uranium and thorium. Thirty-nine isotopes of radon are known [1] and there are no stable ones among them. Thirty-six radon isotopes are artificial isotopes and only three $\left({ }^{219} \mathrm{Rn},{ }^{220} \mathrm{Rn}\right.$ and $\left.{ }^{222} \mathrm{Rn}\right)$ are natural. Natural radon isotopes have their own trivial names like ${ }^{222} \mathrm{Rn}$ is radon $(\mathrm{Rn}),{ }^{220} \mathrm{Rn}$ is thoron (Tn) and ${ }^{219} \mathrm{Rn}$ is actinon (An). Table 1 shows the physical characteristics and sources of naturally occurring isotopes of radon.

As can be seen in the table, ${ }^{222} \mathrm{Rn}$ is the most dangerous radon isotope due to its relatively long half-life and higher quantity of radioactive decay products. It provides a significant irradiation dose due to additional irradiation by alpha and beta radiation of its short-lived decay products, which are forming and decaying in a human body. Moreover, ${ }^{222} \mathrm{Rn}$ has long-lived decay products ${ }^{210} \mathrm{~Pb}(22.3 \mathrm{y})$ and ${ }^{210} \mathrm{Po}(138.4 \mathrm{~d})$ possessing long elimination periods in the human body. Being a heavy inert gas, radon is concentrated mostly in soil, near-ground air and lower floors of buildings [2, 3].

In addition to air, radon is also present in underground water. Typical radon activity in groundwater ranges from $3.7 \mathrm{~Bq} / \mathrm{L}$ to $370 \mathrm{~Bq} / \mathrm{L}$ and is heavily dependent on the area's geology [4]. In areas where uranium content in rocks is low, radon content in groundwater is also low (no more than several dozen $\mathrm{Bq} / \mathrm{L}$ ) [5-7]. However, it is not uncommon 
Table 1. Sources and physical characteristics of naturally occurring isotopes of radon [1]

\begin{tabular}{lccccc}
\hline Isotope & Half-life & Decay mode & $\begin{array}{c}\text { Energy of alpha } \\
\text { particles }[\mathrm{MeV}]\end{array}$ & $\begin{array}{c}\text { Mother } \\
\text { radionuclide }\end{array}$ & $\begin{array}{c}\text { Number of short-lived } \\
\text { decay products }\end{array}$ \\
\hline${ }^{222} \mathrm{Rn}$ & $3.825 \mathrm{~d}$ & alpha & 5.489 & ${ }^{238} \mathrm{U}$ & $2 \alpha, 2 \beta$ \\
${ }^{220} \mathrm{Rn}$ & $55.6 \mathrm{~s}$ & alpha & 6.819 and 6.553 & ${ }^{232} \mathrm{Th}$ & $1 \alpha, 2 \beta$ \\
${ }^{219} \mathrm{Rn}$ & $3.96 \mathrm{~s}$ & alpha & 7.133 & ${ }^{235} \mathrm{U}$ & $2 \alpha, 2 \beta$ \\
\hline
\end{tabular}

to find thousands and tens of thousands of $\mathrm{Bq} / \mathrm{L}$ in water in some countries in Northern Europe, as well as in Czechia and Russia (Ural) [8-10]. According to the United Nations Scientific Committee on the Effects of Atomic Radiation (UNSCEAR), as many as $10 \%$ of water sources used worldwide have radon concentrations exceeding $100 \mathrm{~Bq} / \mathrm{L}$ [11].

Regulations limiting radon content in drinking water vary from country to country. According to the recommendations by the U.S. Environmental Protection Agency [12], the level of radon in drinking water should not be higher than $150 \mathrm{~Bq} / \mathrm{L}$ (4000 pCi/L). Under the Council Directive $2013 / 51$ /Euratom [13], a level of $100 \mathrm{~Bq} / \mathrm{L}$ is recommended for the member states of the European Union. In Russia, the Radiation Safety Standards NRB-99/2009 state that the intervention limit for ${ }^{222} \mathrm{Rn}$ in drinking water is $60 \mathrm{~Bq} / \mathrm{L}$ and the determination of the specific activity of ${ }^{222} \mathrm{Rn}$ in drinking water from underground sources is mandatory.

\section{Experimental}

Natural underground water with radon concentrations of nearly $1300 \mathrm{~Bq} / \mathrm{L}$ was sampled from a spring in the Sverdlovsk region (Ural Mountains, Russia). The salt content of the water samples did not exceed $150 \mathrm{mg} / \mathrm{L}, \mathrm{pH}$ value ranged from 6.5 to 7.5 . Water was sampled into leak-proof bottles and stored overnight to achieve radioactive equilibrium between radon and its short-lived decay products $\left({ }^{218} \mathrm{Po},{ }^{218} \mathrm{At},{ }^{214} \mathrm{~Pb}\right.$, ${ }^{214} \mathrm{Bi}$ and ${ }^{214} \mathrm{Po}$ ). The activity of radon was measured using a scintillation gamma spectrometer Atomteh MKS-1315 AT (Atomteh, Belarus) using the gamma peak of ${ }^{214} \mathrm{Bi}(E=609 \mathrm{keV})$ in the standard Marinelli beaker $(1 \mathrm{~L})$ without sample pretreatment.

In the experiments on radon sorption by activated carbons, $20 \mathrm{~mL}$ of activated carbon was loaded in a sorption column with an inner diameter of $18 \mathrm{~mm}$. The column was washed by tap water to eliminate a fine fraction of the coal. Radon-containing water was loaded through the sorption column using a peristaltic pump. Water sample after sorption was stored in a closed bottle for three to four hours to achieve radioactive equilibrium and the radon activity concentration was measured. Dimensionless values of sorption degree $S$ were calculated in accordance with Eq. (1):

$$
S=\frac{A_{0}-A}{A_{0}}
$$

where $A_{0}$ and $A$ are initial and final activity concentrations of radon in water respectively $[\mathrm{Bq} / \mathrm{L}]$.

In the experiments on sorption of radon decay products by various sorbents, $1 \mathrm{~g}$ of a sorbent was added to $500 \mathrm{~mL}$ of radon-containing water $\left(A_{0}=\right.$ $1000-1300 \mathrm{~Bq} / \mathrm{L})$, shaken for $17 \mathrm{~min}$ and then stored for $3 \mathrm{~min}$ to allow the sorbent settling. After that, the water was filtered through a article filter under vacuum ( $5 \mathrm{~min}$ ) and then measured by a gamma spectrometer for $5 \mathrm{~min}$ in a standard $0.5 \mathrm{~L}$ plastic container. Radon was totally eliminated during sorption and filtering; radioactive decay of radon daughters was taken into account. The values of the gross gamma count rate of the samples were used for the calculation of sorption degrees. The calculation of the sorption degree of radon daughters was performed in accordance with Eq. (1). The lower limit of detection (LLD) under these conditions was $20 \mathrm{~Bq} / \mathrm{L}$.

\section{Results and discussion}

Choosing the sorption materials for the elimination of radon and its decay products from water

In most cases, radon and radon daughters are eliminated from water by aeration or filtration through various sorbents, in particular, activated carbon.

The aeration method is simple and efficient and does not require any chemicals. However, when this method is used, radon is released into the ambient air and the system requires power for pump operation.

When water is filtered through activated carbon, radon and radon daughters are accumulated in it. As a result, the filter becomes a gamma radiation source. To ensure safe operation, such filters have to be shut down from time to time for natural radon decay. When a filter is used on a continuous basis, the dose rate depends on radon concentrations in untreated water, total water consumption and filter capacity, and may reach dangerous levels of several hundred microsieverts per hour, which makes the treatment process further radiation hazardous.

Four types of activated carbons were tested in the work:

- activated carbon from coconut shell Carbotech (Germany) after being washed using inorganic salts;

- activated carbon from coconut shell Carbotech (Germany) impregnated by $\mathrm{Ag}+$;

- activated carbon from coconut shell NWC (Malaysia);

- birch activated carbon BAU (Russia).

The results of sorption tests are presented at the diagram (Fig. 1).

The results have shown that the Carbotech activated carbon provided the best radon elimination among the carbons being studied. The presence of silver does not affect the sorption degree of radon 


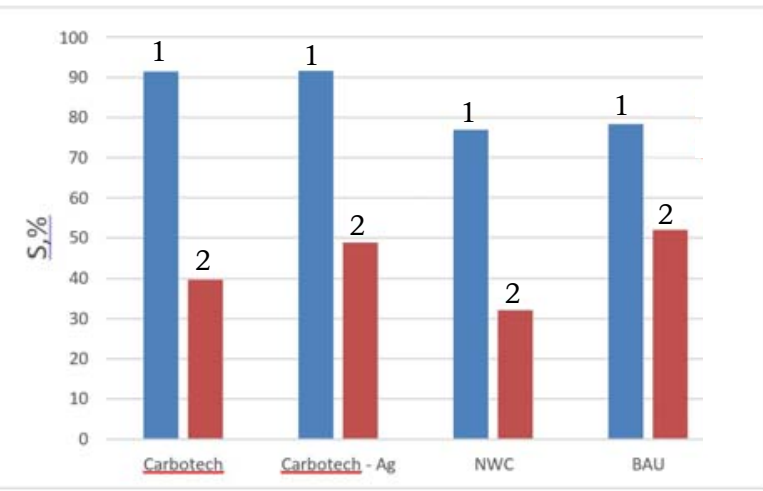

Fig. 1. Degrees of sorption of ${ }^{222} \mathrm{Rn}(1)$ and its decay products $\left({ }^{214} \mathrm{Bi}+{ }^{214} \mathrm{~Pb}\right)(2)$ by various activated carbons in column tests.

by the Carbotech activated carbon. However, the degrees of sorption of radon decay products were significantly lower and did not exceed 30\% to 50\%. Therefore, the installation for water treatment should contain both carbon layer for radon elimination and an inorganic sorbent for sorption of radon decay products. We have tested 23 types of sorbents being produced by EKSORB Ltd. for the elimination of radon decay products in batch conditions. The results are presented in Table 2.

Among the sorbents tested, RATZIR sorbent was chosen for the elimination of radon decay products from water.

\section{Technology for removal of radon and radon daughters from water}

The article presents the results of tests of a system for the removal of radon and radon daughters from water patented by EKSORB. This is achieved by filtering water through RATZIR sorbent, followed by periodic load regeneration.

The key element of the proposed system is RATZIR, a zirconium hydroxide-based inorganic sorbent developed by Scientific Production Enterprise EKSORB Ltd. for transition metal ion sorption, which is used in the system as filtering material, in addition to activated carbon.

For three years, the system has been treating water with the initial radon level exceeding $1500 \mathrm{~Bq} / \mathrm{L}$ to standard levels. The amount of activated carbon to be loaded into the system is $70 \mathrm{~L}$ and the amount of RATZIR is $15 \mathrm{~L}$. The layer of the sorbent is located in the middle of the column, between the layers of activated carbon. The estimated water consumption is 1000 liters per day. The column is backwashed once every month. When backwashing a column with a sorbent, three to five volumes of a sorption column of hot water without circulation are used, and then this water is collected in an underground storage tank.

Before backwashing, the level of exposure rate on the surface of the column near the layer of activated carbon reached $0.6 \mu \mathrm{Sv} / \mathrm{h}$; in the central part of the column near the layer of RATZIR, $20 \mu \mathrm{Sv} / \mathrm{h}$, which is 100 times higher than background levels. After backwashing, the level of background gamma
Table 2. The results of testing various types of sorbents for the elimination of ${ }^{222} \mathrm{Rn}$ decay products from drinking water

\begin{tabular}{rcc}
\hline No. & $\begin{array}{c}\text { Type } \\
\text { of a sorbent }\end{array}$ & $\begin{array}{c}\text { Degree of sorption } \\
\text { of gamma-emitting radon decay } \\
\text { products }\left({ }^{214} \mathrm{Bi}+{ }^{214} \mathrm{~Pb}\right)[\%]\end{array}$ \\
\hline 1 & R-Ac V.15 & 53.7 \\
2 & Mg-Ac, 23X & 79.9 \\
3 & SH2 & 95.2 \\
4 & MnO - Ac & $\approx 100$ \\
5 & CuS-Ac, 3:1 & 80.7 \\
6 & CuS-Ac, 3:0.2 & 76.6 \\
7 & SPP & 81.9 \\
8 & Ac & 77.2 \\
9 & CuS-Ac & 90.7 \\
10 & BAU & 80.5 \\
11 & NWC & 60.6 \\
12 & CuS-Ac, 6:6 & $\approx 100$ \\
13 & CuS-Ac & 78.4 \\
14 & RATZIR & $\approx 100$ \\
15 & Mix15 & 96.4 \\
16 & Mix16 & 91.8 \\
17 & Mix17 & 93.8 \\
18 & Mix18 & 55.0 \\
19 & Mix19 & 83.7 \\
20 & Mix20 & 85.7 \\
21 & Mix21 & 54.1 \\
22 & Mix22 & 88.7 \\
23 & Mix23 & 81.9 \\
\hline
\end{tabular}

radiation was down to background levels. Water used for backwashing is drained to an underground storage tank with a capacity of $3 \mathrm{~m}^{3}$, where it is left for about one month; and then it is dumped to the sewerage system.

RATZIR makes it possible to extract radon daughters from water, which are a greater radiation hazard for the gastrointestinal tract as alpha emitters than radon itself.

Another feature of the new system is the possibility to reduce the radiation hazard from the filtration column where radionuclides are accumulated. To reduce the dose rate from the column, the column is regularly backwashed with water heated to a temperature of $50^{\circ} \mathrm{C}$ to $85^{\circ} \mathrm{C}$. After that, the water is collected in a sump tank and kept there for at least two weeks until radon and radon daughters decay.

The amount of water used for backwashing is one to five times the amount of sorbent materials. Compared to similar products, our system offers the following advantages:

1. The system reliably captures radon and radon daughters such as lead and bismuth and guarantees the best possible removal of natural radionuclides from water (up to $99 \%$ ).

2. Since the system does not release radon into the indoor and outdoor air, it ensures the safety of people around and is not a cause of concern for neighbours.

3. The engineering solutions used in the system help to avoid excessive accumulation of radionuclides in the system and prevent overexposure near the system. 

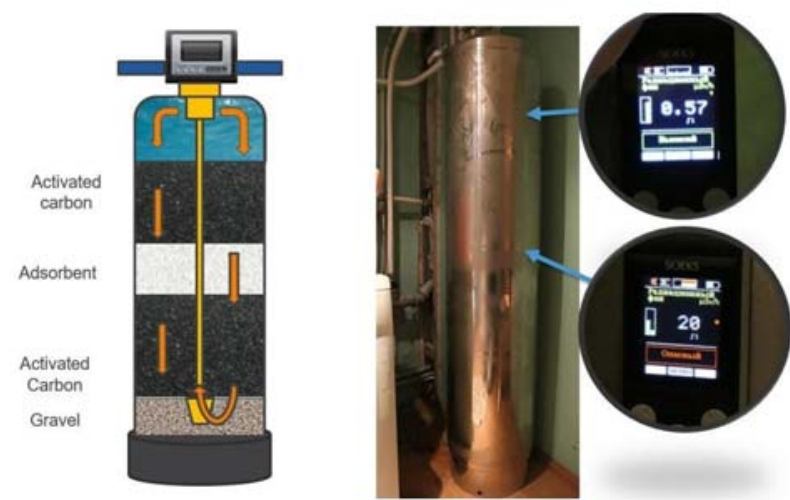

Fig. 2. Scheme (left) and photo (right) of the existing radon removal system, showing background gamma radiation on the surface during the system's operation.

4. The system is simple, reliable and quiet during operation. It does not require additional power. Moreover, it can be easily integrated into the existing water treatment system.

In the future, a homogenized mixture of activated carbon and RATZIR sorbent may be loaded into the filtration column to reduce the level of background gamma radiation from the column. Alternatively, a double-column patented by EKSORB may also be used, where the more active sorbent RATZIR is located inside the column with less active carbon.

\section{Conclusions}

The article presents the results of the operation of a system that removes radon from water. In reality, such a system has already been in operation for three years in a private household in Sverdlovsk Oblast (Ural region, Russia). The pretreatment level of radon in water from a private well is about $1500 \mathrm{~Bq} / \mathrm{L}$ whereas the post-treatment level is lower than $60 \mathrm{~Bq} / \mathrm{L}$.

In addition, the patented backwash system helps to avoid excessive accumulation of radionuclides in the system and prevent overexposure near the system.

\section{References}

1. Magill, J., Pfenning, G., Dreher, R., \& Soti, Z. (2012). Chart of the nuclides (KarlsruherNuclidkarte) (8th ed). Karlsruhe, Germany: Nucleonica GmbH.

2. Podstawczyńska, A., \& Pawlak, W. (2016). Soil heat flux and air temperature as factors of radon (Rn-222) concentration in the near-ground air layer. Nukleonika, 61(3), 231-237. DOI: 10.1515/nuka-2016-0039.
3. Sóki, E., \& Csige, I. (2016). Radon in the dry carbon dioxide spa of Mátraderecske, Hungary. Nukleonika, 61(3), 245-249. DOI: 10.1515/nuka-2016-0041.

4. Seminsky, K., \& Seminsky, A. (2016). Radon in underground waters of Baikal and Transbaikalia: spatialtemporal variations. Geodynamics \& Tectonophysics, 7(3), 477-493. DOI: 10.5800/GT-2016-7-3-0218.

5. Wieprzowski, K., Bekas, M., Waśniewska, E., Wardziński, A., \& Magiera, A. (2018). Radon ${ }^{222} \mathrm{Rn}$ in drinking water of West Pomeranian Voivodeship and KuyavianPomeranian Voivodeship, Poland. Nukleonika, 63(2), 43-46. DOI: 10.2478/nuka-2018-0005.

6. Alomari, A. H., Saleh, M. A., Hashim, S., Alsayaheen, A., \& Abdeldin, I. (2019). Activity concentrations of ${ }^{226} \mathrm{Ra},{ }^{228} \mathrm{Ra},{ }^{222} \mathrm{Rn}$ and their health impact in the groundwater of Jordan. J. Radioanal. Nucl. Chem., 322, 7-8. DOI: 10.1007/s10967-019-06686-4

7. Singh, P., Singh, P., Sahoo, B. K., \& Bajwa, B. S. (2016). A study on uranium and radon levels in drinking water sources of a mineralized zone of Himachal Pradesh, India. J. Radioanal. Nucl. Chem., 309, 541-549. DOI: 10.1007/s10967-015-4629-9.

8. Skeppstrom, K., \& Olofsson, B. (2006). A prediction method for radon in groundwater using GIS and multivariate statistics. Sci. Total. Environ., 367, 666-680. DOI: 10.1016/j.scitotenv.2006.02.044.

9. Lopes, I., Vesterbacka, P., \& Kelleher, K. (2017). Comparison of radon $(\mathrm{Rn}-222)$ concentration in Portugal and Finland underground waters. J. Radioanal. Nucl. Chem., 311(3), 1867-1873. DOI: 10.1007/s10967017-5166-5.

10. Semenishchev, V. S., Remez, V. P., \& Voronina, A. V. (2018). Use of the Sorben-Tec system for rapid dosimetric evaluation of ${ }^{222} \mathrm{Rn}$ level in drinking water. $J$. Radioanal. Nucl. Chem., 325(3), 1311-1318. DOI: 10.1007/s10967-018-6038-3.

11. United Nations Scientific Committee on the Effects of Atomic Radiation. (2000). Sources and effects of ionizing radiation. United Nations Scientific Committee on the Effects of Atomic Radiation UNSCEAR 2000 Report to the General Assembly, with Scientific Annexes. Vol. 1: Sources. New York: United Nations.

12. United States Environmental Protection Agency (1991). Radon Measurement Proficiency (RMP) Program Handbook. Washington, D.C.: Office of Radiation Programs. (EPA 520/1-91-006).

13. European Union. (2013). Council Directive 2013/51/ Euratom of 22 October 2013. Laying down requirements for the protection of the health of the general public with regard to radioactive substances in water intended for human consumption. Official Journal of the European Union, 7.11.2013, L 296/12. Retrieved January 28, 2020, from https://eur-lex.europa.eu/ legal-content/EN/TXT/PDF/?uri=CELEX:32013L0 $051 \&$ rid $=7$. 